\title{
Labor or Capital Income Tax for Growth in an Aging Society
}

\author{
Yusuke Miyake $^{1}$ \\ ${ }^{1}$ Nippon Bunri University, 1727 Ichigi, Oita city, 870-0397, Oita Prefecture, Japan. \\ Correspondence: Yusuke Miyake, Nippon Bunri University, 1727 Ichigi, Oita city, 870-0397, Oita Prefecture, Japan.
}

Received: August 10, 2020

Accepted: September 7, 2020

Available online: September 9, 2020

doi:10.11114/aef.v7i5.4969

URL: https://doi.org/10.11114/aef.v7i5.4969

\begin{abstract}
This study analyzes whether taxation of labor income or capital income maximizes growth rates, with labor-argument type model, in an aging society. There are certain conditions that maximize growth rates which are indicated by the share of public capital-public pensions. The results of this analysis taxing capital income is better in an economy where private capital is drastically larger than the public capital found in an aging society.
\end{abstract}

Keywords: private capital, public capital, labor income, capital income

JEL classification: E60, H20, H54

\section{Introduction}

It is a well-known fact that the trend of lower birthrates and an aging population has accelerated. According to the Cabinet Office, by 2050, Japan will become a super-aged society, where one out of 2.5 people will be elderly (aged 65 or older). ${ }^{1}$ A demographic survey by the Ministry of Health, Labour and Welfare (MHLW), indicated that the total fertility rate fell to 1.42 in 2018. What has caused the aging of population and decreasing birthrate so rapidly? Why has the trend not shown any sign of stopping, despite implementation of diverse measures and policies? It is thought that the situation discussed above is strongly associated with socioeconomic backgrounds of the Japanese population. People who faced the so-called employment ice age (after the economic bubble implosion in(1991-1993) entered a labor market, that was predominantly a buyer's market with less career options. Then, the economic growth rate became stagnant with low stock prices, which, along with other factors such as the deterioration of corporate profit margins and labor environments, led to corrupted work-life balance. Consequently, employment systems of private businesses started to change, as represented by the increase in temporary employment, the ending of permanent employment system, and changes in the retirement allowance systems (early retirement programs and abolishment of retirement allowance system), etc. From a long-term perspective, workers should determine their spending based on their estimated lifetime income. According to the overlapping generation model advocated by Diamond (1965), a person's lifetime income consists of incomes from two periods, namely young and old. Policies relating to pensions include increasing the age for the start of pension benefits, lowering of the retirement pension for active employees, and increasing pension premiums. The national pension premiums have consistently increased since introduction of the system in 1961. In fact, the present premiums are more than twice as much as those in $1990 .{ }^{2}$ Meanwhile, since 2020 , the amount of pension benefits for new pensioners have decreased. An important point raised in resolving these issues in Japan is the relation between financial sources and benefits. In other words, what type of tax should be imposed and how should it be distributed. These factors are determined based on trade-off between (1) efficiency and (2) fairness. The first point to be considered is (1) efficiency. To maximize efficiency, one needs to maximize the economic growth rate. This study establishes a model based on the neoclassical theory that capital growth will drive up the gross domestic product (GDP) and lead to a greater growth rate or the whole nation. With respect to (2) fairness social welfare in household finance of the nation needs to be considered. Maximized social welfare, at a scale of the whole nation, is not

\footnotetext{
1 "Situations of Aging" (Japanese), Cabinet Office website (https://www8.cao.go.jp/kourei/whitepaper/w-2012/zenbun/pdf/1s1s_1.pdf) (accessed on June 15, 2020)

2 "Changes in National Health Insurance Premiums" (Japanese), Japan Pension Service website

(https://www.nenkin.go.jp/service/kokunen/hokenryo-hensen/index.html) (accessed on June 17, 2020)
} 
necessarily a sign of maximized welfare in the domestic accounts of individual households because there are inter- and intra-generational gaps. The key is to minimize the gaps and work out policies to maximize both growth rate and welfare. In the body of this article, the endogenous growth model (Romer(1986)) is used to simulate introduction of public capitals proposed by Barro (1990), Barro and Sala-i-Martin (1992), Futagami et al. (1993), Turnovsky (1997) and Yakita (2008). While public pension is introduced with taxation on both labor income and capital income as financial sources in Maebayashi (2013), I hereby establish separate model with taxation of capital income and labor income in order to analyze how they impact growth rate and social welfare.

Intuitively when an increase in capital occurs along with a rise in GDP, and is greater than the decrease in private capital variables, it will grow continuously. The scenario of utilizing capital income tax will grow with no conditions. However, the scenario involving labor income tax requires a strict condition, which is indicated by the share of government expenditure on public capital investment. This also includes the expenditure on public pensions. In today's aging society, the welfare of the elderly, which is the majority of nationals, should be the top priority when the welfare of the entire nation is taken into account. An increase in pension benefits should improve the welfare of the elderly generation. However, from a long-term perspective and in the interest of future generations, as well as to boost productivity, public capital investments are one of the important driving factors for a sustainable growth rate. Furthermore, the increased production efficiency of the current working generations will increase future financial resources, which can be used to increase pension benefit. Hence, the government's cautious long-term investments, rather than conventional public capital investments, is the decisive factor for the growth rate and social welfare of Japan and the rest of the world. Specific analyses of public capital investments are left for further studies.

This study is based on Maebayashi (2013). He indicated the relative scale of capital (private-public) will stably converge on the steady-state. Kamiguchi and Tamai (2019) showed the optimal tax rate maximize growth rate and social welfare subject to the public finance. But these analyzes are considered to tax both capital income and labor income. They don't make compare the two types of tax and how these affect growth and social welfare. In this study, I clarify the different effects of these types of taxes on growth and welfare. If government emphasizes growth, then capital income tax is the better option. However, if the government emphasizes welfare, labor income tax is the better option. The remainder of this study is organized as follows. The next section constructs a dynamic system of private capital and public capital formation into the same two periods, namely young and old, using the over-lapping generations model, as advocated by Diamond (1965). These derive the dynamics of the ratio in private-public capital. Both private capital and public capital are formalized as stock variables.

\section{Model}

\subsection{Individuals}

I assume homogeneous consumers and no population growth $\left(L_{t}=L_{t+1}=L\right)$. The consumer obtains consumption in working and old age periods and supply labor inelastically in first period where I assume every consumer has one unit of labor. He allocates income for consumption and savings in first period and in the second period consumes all income of savings and a public pension with no bequest. I assume a perfect insurance market by Yaari (1965) and Blanchard (1985) and each individual faces the survival rate $\beta \in(0,1)$. I assume logarithmic linear utility function and lifetime budget constraint is shown as follows where time preference is indicated by $\rho \in(0,1)$ and $\tau \in(0,1)$ indicates the capital income tax.

$$
\begin{gathered}
\max \quad u_{t}=\log c_{t}+\beta \rho \log d_{t+1} \\
w_{t}=c_{t}+s_{t} \\
d_{t+1}=\frac{s_{t}\left[1+r_{t+1}(1-\tau)\right]}{\beta}+\frac{p_{t+1}}{\beta} \\
\text { s.t } \quad w_{t}+\frac{p_{t+1}}{\left[1+r_{t+1}(1-\tau)\right]}=c_{t}+\frac{\beta d_{t+1}}{\left[1+r_{t+1}(1-\tau)\right]}
\end{gathered}
$$

Optimal consumption in every period and saving are assigned in the following equations. 


$$
\begin{gathered}
c_{t}^{*}=\frac{w_{t}\left[1+r_{t+1}(1-\tau)\right]+p_{t+1}}{\rho\left[1+r_{t+1}(1-\tau)\right]+\left[\left(1+r_{t+1}(1-\tau)\right]\right.} \\
d_{t+1}^{*}=\frac{\rho\left[1+r_{t+1}(1-\tau)\right]}{\beta} c_{t}^{*}+\frac{p_{t+1}}{\beta} \\
s_{t}^{*}=w_{t}\left\{1-\frac{\left[1+r_{t+1}(1-\tau)\right]+p_{t+1}}{\left[1+r_{t+1}(1-\tau)\right](\rho+1)}\right\}
\end{gathered}
$$

\subsection{Production}

I consider Cobb-Douglas production function where labor increase with a public capital investment, as per Romer (1986), and the firm's product is a homogeneous good. Inputs are capital and labor. The function is as follows.

$$
\begin{gathered}
Y_{t}=K_{t}^{\alpha}\left(A_{t} L_{t}\right)^{1-\alpha} \\
A_{t}=\frac{G_{t}}{L_{t}}
\end{gathered}
$$

I assume a perfect competitive market and solve the problem of profit maximization as follows.

$$
\begin{gathered}
\alpha\left(\frac{K_{t}}{G_{t}}\right)^{\alpha-1}=r_{t} \\
(1-\alpha)\left(\frac{K_{t}}{G_{t}}\right)^{\alpha} \frac{G_{t}}{L}=w_{t}
\end{gathered}
$$

\subsection{Government}

Government tax the capital income and divides tax revenue for public capital investment and pension. $E$, $P$ show each public capital investment and pension. The share for public capital investment shown as $\varphi \in(0,1) . \tau \in(0,1)$ indicates capital income tax. Depreciation rate of private and public capital is assumed 1. Budget constraint of government is shown as follows.

\subsection{Equilibrium}

$$
\begin{gathered}
E_{t}+P_{t}=K_{t} r_{t} \tau \\
E_{t}=G_{t+1}-G_{t}=\varphi r_{t} \tau K_{t} \\
P_{t}=(1-\varphi) r_{t} \tau K_{t}
\end{gathered}
$$

This model has three markets which are goods, labor and capital. I consider only capital market by Walras' law with equilibrium condition (15).

I substitute (7) for (15) and obtain (16).

$$
s_{t} L=K_{t+1}
$$

$$
K_{t+1}=w_{t}\left\{1-\frac{\left[1+r_{t+1}(1-\tau)\right]+p_{t+1}}{\left[1+r_{t+1}(1-\tau)\right](\rho+1)}\right\} L
$$


I substitute (10),(11) for (16) and obtain (17).

$$
K_{t+1}=\left\{(1-\alpha)\left(\frac{K_{t}}{G_{t}}\right)^{\alpha}\left(\frac{G_{t}}{L}\right)-\frac{(1-\alpha)\left(\frac{K_{t}}{G_{t}}\right)^{\alpha}\left(\frac{G_{t}}{L}\right)\left[1+\alpha\left(\frac{K_{t+1}}{G_{t+1}}\right)^{\alpha-1}(1-\tau)\right]+(1-\varphi) \tau \alpha\left(\frac{K_{t+1}}{G_{t+1}}\right)^{\alpha-1} K_{t+1}}{\left[1+\alpha\left(\frac{K_{t+1}}{G_{t+1}}\right)^{\alpha-1}(1-\tau)\right](\rho+1)}\right\} L
$$

\subsection{Dynamics}

The ratio of a private and public capital shows as $x=\frac{K}{G}$. I assume $x \geq 1$, which means private capital is larger than or equal to public capital. The growth rate of private capital is as follows.

$$
\frac{K_{t+1}}{K_{t}}=\frac{\rho(1-\alpha) x_{t}^{\alpha-1}}{(1+\rho)-\frac{(1-\varphi) \tau \alpha x_{t+1}^{\alpha-1} x_{t}^{\alpha} G_{0}}{\left[1+\alpha x_{t+1}^{\alpha-1}(1-\tau)\right]}}
$$

The growth rate of public capital is shown as follows with (13).

$$
\frac{G_{t+1}}{G_{t}}=\frac{\varphi \alpha \tau}{\left(1-\delta_{G}\right)} x_{t}^{\alpha}+1
$$

The growth rate of $x$ is indicated by (20).

$$
\frac{x_{t+1}}{x_{t}}=\frac{\frac{K_{t+1}}{K_{t}}}{\frac{G_{t+1}}{G_{t}}}=\frac{\rho(1-\alpha) x_{t}^{\alpha-1}\left[1+\alpha x_{t+1}^{\alpha-1}(1-\tau)\right]}{\left(\varphi \alpha \tau x_{t}^{\alpha}+1\right)\left\{\left[1+\alpha x_{t+1}^{\alpha-1}(1-\tau)\right](1+\rho)-(1-\varphi) \tau \alpha x_{t+1}^{\alpha-1} x_{t}^{\alpha} G_{0}\right\}}
$$

\section{Policy Maximizing the Long-Run Growth Rate}

\subsection{Steady State of Relative Value for Private and Public Capital}

I fully differentiate (20) because of the derivation of dynamics of $x$.

$$
\begin{gathered}
\frac{d x_{t+1}}{d x_{t}}=\frac{A}{B} f\left(A\left(x_{t}\right), B\left(x_{t}\right)\right)>0 \\
A=(1+\rho) \alpha^{2} \tau \varphi x_{t+1}+(1+\rho)(1-\tau) \alpha^{3} \varphi \tau x_{t}^{\alpha-1} x_{t+1}^{\alpha}-2 \alpha(1-\varphi) \tau^{2} \alpha^{4} x_{t+1}^{\alpha} x_{t}^{2 \alpha-1} G_{0}-(1-\varphi) \tau \alpha x_{t}^{2 \alpha-1} G_{0} \\
-\varphi \alpha^{2} \tau x_{t}^{\alpha-1}(1+\rho) x_{t+1}-\varphi \alpha^{3} \tau(1-\alpha) x_{t}^{\alpha-1} x_{t+1}^{\alpha}+6(1-\varphi) \tau^{2} \alpha x_{t+1}^{\alpha} x_{t}^{2 \alpha-1} G_{0}+(1-\varphi) \tau \alpha^{2} x_{t+1}^{\alpha} \\
-\alpha^{2}(1-\alpha)(1-\tau) x_{t}^{\alpha-1} G_{0}<0 \\
B=-(1+\rho)-(1-\varphi) \tau^{2} \alpha^{3} x_{t}^{2 \alpha} x_{t+1}^{\alpha-1}(1-\tau)(1+\rho) G_{0}+3 \varphi \tau(1+\rho)(1-\tau) \alpha x_{t}^{\alpha} x_{t+1}^{\alpha-1}+\varphi \alpha \tau x_{t}^{\alpha}(1+\rho) \\
-(1+\rho)(1-\tau) \alpha^{2} x_{t+1}^{\alpha-1}<0
\end{gathered}
$$

The second derivative of (21) is derived as follows. 


$$
\begin{gathered}
\frac{d^{2} x_{t+1}}{\left(d x_{t}\right)^{2}}=\frac{d f(A, B)}{d x_{t}}=\frac{B A^{\prime}-B^{\prime} A}{B^{2}}<0 \\
\lim _{x_{t} \rightarrow 0} \frac{d x_{t+1}}{d x_{t}}=\infty \quad \lim _{x_{t} \rightarrow \infty} \frac{d x_{t+1}}{d x_{t}}=0
\end{gathered}
$$

In the first quadrant with horizontal axis $x_{t}$ and vertical axis $x_{t+1}, x$ will converge to the steady state $x^{*}$ if (21),(24) and (25) [Inada-condition] are fulfilled. (Fig.1) $x$ will converge stably to steady state.

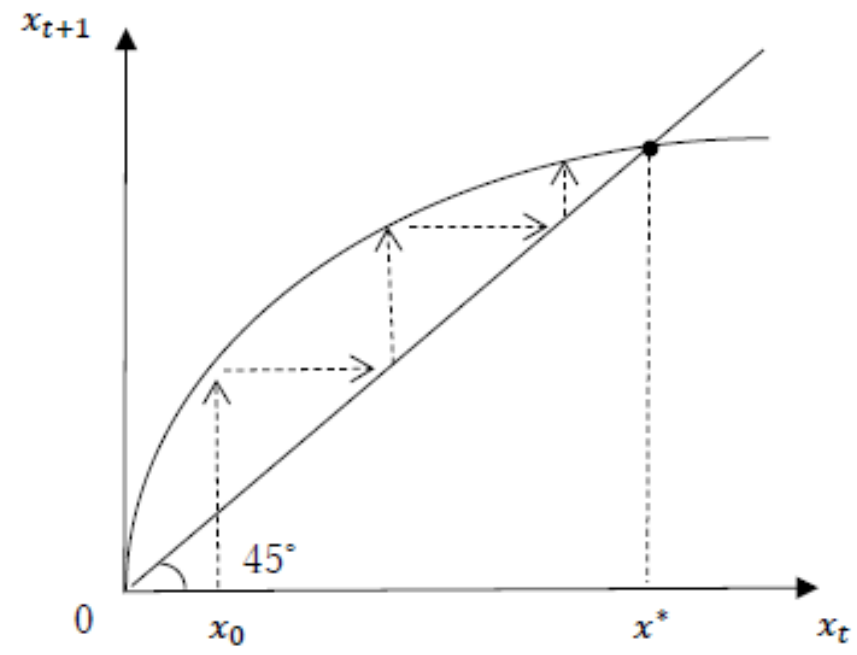

Figure 1. Dynamics of $x$.

The ratio of private-public capital will increase if the sign of (21) is positive. The steady state of $x$ is shown as $x^{*}$. If equation (26) satisfies with $x^{*}$ the growth rate of GDP, private and a public capital, will be the same.

$$
\begin{gathered}
(1-\alpha)\left[\rho\left(x^{*}\right)^{\alpha-1}+\alpha \rho\left(x^{*}\right)^{2 \alpha-2}(1-\tau)\right] \\
=\left[\tau \varphi \alpha\left(x^{*}\right)^{\alpha}+1\right]\left\{\left[1+\alpha\left(x^{*}\right)^{\alpha-1}(1-\tau)\right](1+\rho)-(1-\varphi) \tau \alpha\left(x^{*}\right)^{2 \alpha-1} G_{0}\right\} \\
g=\frac{Y_{t+1}}{Y_{t}}=\frac{K_{t+1}}{K_{t}}=\frac{G_{t+1}}{G_{t}}
\end{gathered}
$$

\subsection{Optimal Tax Rate for Maximizing Growth}

The growth rate at steady state is shown as follows by (27). I derive the effect of tax on the growth.

Where $\frac{\tau}{\left(x^{*}\right)} \frac{d x^{*}}{d \tau}$ indicates the elasticity of tax for $x^{*}$ and $\frac{d x^{*}}{d \tau}$ must be positive for $\frac{d g}{d \tau}>0$. 


$$
\begin{gathered}
\frac{d g}{d \tau}=\varphi \alpha\left[1+\alpha\left(x^{*}\right)^{\alpha} \frac{\tau}{\left(x^{*}\right)} \frac{d x^{*}}{d \tau}\right] \\
\frac{d x^{*}}{d \tau}=\frac{A}{B}
\end{gathered}
$$

Here $x^{*}$ is shown as $x$ for simplicity.

$$
\begin{gathered}
A=x^{\alpha} \alpha(1+\rho) \varphi+\alpha^{2} x^{2 \alpha-1} \varphi-2(1+\rho) x^{2 \alpha-1} \tau \alpha^{2} \varphi-(1-\varphi) \alpha x^{2 \alpha-1} G_{0}-\alpha x^{\alpha-1}(1+\rho)+\alpha \rho x^{2 \alpha-2}(1-\alpha) \\
<0 \\
B=-(1-\alpha)^{2} x^{2 \alpha-3}[2 \alpha \rho(1-\tau)+1]-\tau \alpha^{2}(1+\rho) x^{\alpha-1}-(2 \alpha-1)(1+\rho) \tau \alpha^{2} x^{2 \alpha-2} \varphi-\alpha(1-\alpha)(1+\rho) x^{\alpha-1} \\
+(2 \alpha-1) \tau \alpha x^{2 \alpha-2}\left[(1+\rho) \tau \alpha \varphi+(1-\varphi) G_{0}\right]<0 \quad \text { with } \alpha \leq 0.5
\end{gathered}
$$

The growth rate will increase with no condition in the case of capital income tax, which depends on capital increases together with a rise in GDP. I consider two effects, which are: "A: push-up effect" and "B: reduction effect" "A" means that the GDP is pushed-up by the capital income tax increase, through the increase of tax, which makes labor productivity more efficient. On the other hand, " $\mathrm{B}$ " indicates the private capital reduction effect. There are two routes in this effect. Firstly, the decrease in income gains with tax reduces savings. Secondly, an increase in public pension leads to increase in income in the $2^{\text {nd }}$ period and decline saving. In the case of capital income tax, the effect " $\mathrm{A}$ " exceeds the effect "B" anytime. Sustainable growth will then be possible with no conditions.

\section{Proposition 1.}

The growth rate will be positive if the elasticity of capital income tax for $x^{*}$ is to be positive. For that, no condition is required.

Optimal capital income tax is shown as below.

$$
\tau^{*}=\frac{\varphi \alpha\left(x^{*}\right)^{\alpha-2}-\frac{\varphi \alpha L^{2 \alpha}}{K_{t}\left(G_{0}\right)^{\alpha}}}{\frac{\varphi \alpha}{K_{0}(1-\alpha)}\left(\frac{G_{0}}{L}\right)^{\alpha}+\alpha \varphi L+\frac{\varphi \tau \alpha\left(x^{*}\right)^{\alpha-1} L^{2 \alpha}}{K_{0} G_{0}{ }^{\alpha}}-\varphi \tau \alpha \frac{G_{0}^{\alpha}}{K_{0}}}
$$

\section{The Case of Labor Income Tax}

\subsection{Individuals}

Optimal consumption in working and retire periods and savings are as follows. Here, I indicate labor income tax as $\tau$.

$$
\begin{gathered}
c_{t}^{*}=\frac{w_{t}(1-\tau)\left[1+r_{t+1}\right]+p_{t+1}}{(1+\rho)\left[1+r_{t+1}\right]} \\
d_{t+1}^{*}=\frac{\rho r_{t+1}+p_{t+1}}{\left(\frac{1}{\rho}+\beta\right)}
\end{gathered}
$$




$$
s_{t}^{*}=w_{t}(1-\tau)-\frac{w_{t} r_{t+1}(1-\tau)+p_{t+1}}{\left(\frac{1}{\rho}+\beta\right) \rho r_{t+1}}
$$

\subsection{Government}

Government expenses for public capital investment and pension. The share for public capital investment is shown as $\varphi \in(0,1)$.

$$
\begin{gathered}
E_{t}+P_{t}=L w_{t} \tau \\
E_{t}=G_{t+1}-G_{t}=\varphi w_{t} \tau L \\
P_{t}=(1-\varphi) w_{t} \tau L
\end{gathered}
$$

\subsection{Dynamics}

The growth of a private capital is shown as follows.

$$
\begin{gathered}
\frac{K_{t+1}}{K_{t}}=\frac{\left(x_{t}\right)^{\alpha-1}(1-\alpha)(1-\tau)\left[1-\frac{L}{(1+\rho \beta) \alpha}\right]}{\left[1-\frac{(1-\varphi)(1-\alpha) \tau}{(1+\rho \beta) \rho \alpha L}\right]} \\
\mathrm{g}=\frac{G_{t+1}}{G_{t}}=(1-\alpha)\left(x_{t}\right)^{\alpha} \varphi \tau+1
\end{gathered}
$$

The following shows the growth rate of $x$.

$$
\frac{x_{t+1}}{x_{t}}=\frac{\frac{K_{t+1}}{K_{t}}}{\frac{G_{t+1}}{G_{t}}}=\frac{(1-\alpha)(1-\tau)\left[1-\frac{L}{(1+\rho \beta) \alpha}\right]}{\left[(1-\alpha) \varphi \tau\left(x_{t}\right)^{\alpha}+1\right]\left[1-\frac{(1-\varphi)(1-\alpha) \tau}{(1+\rho \beta) \rho \alpha L}\right]}\left(x_{t}\right)^{\alpha-1} \lim _{x_{t} \rightarrow 0} \frac{x_{t+1}}{x_{t}}=0
$$

$x$ will grow up if the condition (43) is fulfilled.

$$
\begin{gathered}
\frac{d x_{t+1}}{d x_{t}}=\frac{A}{B}=f\left(A\left(x_{t}\right), B\left(x_{t}\right)\right) \\
\varphi<1-\frac{(1+\rho \beta) \rho \alpha L}{(1-\alpha) \tau} \\
A=\alpha(1-\tau)(1-\alpha)\left(1-\delta_{G}\right)\left[1-\frac{L}{(1+\rho \beta) \alpha}\right]\left(x_{t}\right)^{\alpha-1}+(1-\alpha)^{2} \tau \alpha \varphi\left(x_{t}\right)^{\alpha-2} x_{t+1}\left[1-\frac{(1-\varphi)(1-\alpha) \tau}{(1+\rho \beta) \rho \alpha L}\right] \\
B=\left[(1-\alpha) \tau \alpha \varphi\left(x_{t}\right)^{\alpha-1}+1\right]\left[1-\frac{(1-\varphi)(1-\alpha) \tau}{(1+\rho \beta) \rho \alpha L}\right]
\end{gathered}
$$




$$
\begin{gathered}
\frac{d^{2} x_{t+1}}{\left(d x_{t}\right)^{2}}=\frac{d f(A, B)}{d x_{t}}=\frac{B A^{\prime}-B^{\prime} A}{B^{2}}<0 \\
\lim _{x_{t} \rightarrow 0} \frac{d x_{t+1}}{d x_{t}}=\infty \quad \lim _{x_{t} \rightarrow \infty} \frac{d x_{t+1}}{d x_{t}}=0
\end{gathered}
$$

In the first quadrant with horizontal axis $x_{t}$ and vertical axis $x_{t+1}, x$ will converge to the steady state $x^{*}$ if (43), (46) and (47) are fulfilled (Fig.2). $x$ will converge stably to steady state.

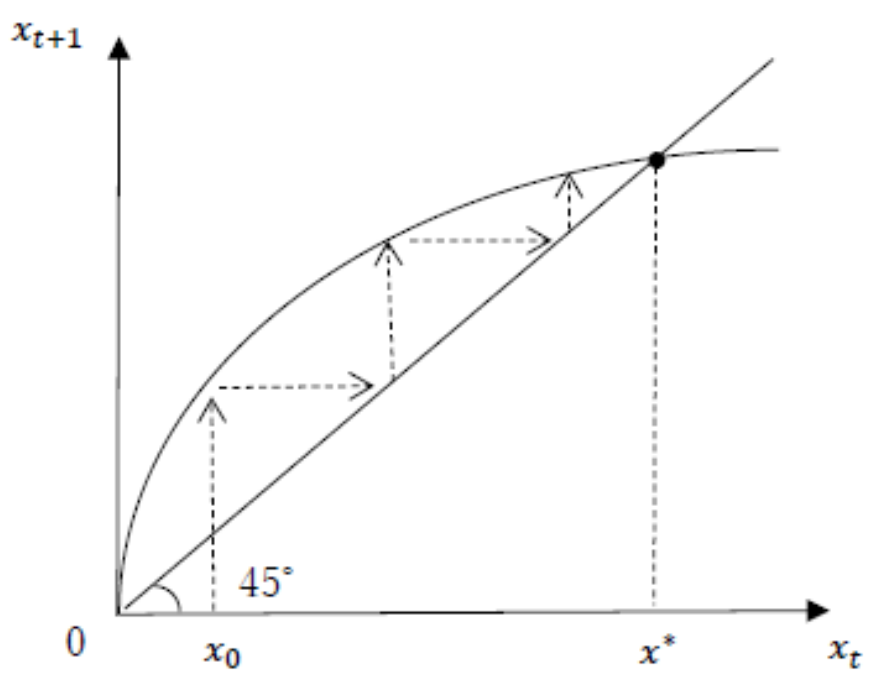

Figure 2. Dynamics of $x$.

\subsection{Policy Maximizing the Long-Run Growth Rate}

I analyze the effect of taxing labor income on the growth and the steady state of $x$ is shown as $x^{*}$.

$$
\begin{gathered}
\frac{d g}{d \tau}=\frac{\varphi(1-\alpha)\left(x^{*}\right)^{\alpha}}{\left(1-\delta_{G}\right)}\left[\alpha \frac{\tau}{x^{*}} \frac{\boldsymbol{d} \boldsymbol{x}^{*}}{\boldsymbol{d} \boldsymbol{\tau}}+1\right] \\
\frac{\boldsymbol{d} \boldsymbol{x}^{*}}{\boldsymbol{d} \boldsymbol{\tau}}=\left[\frac{\left(x^{*}\right)^{\alpha}\left[1-\frac{(1-\varphi)(1-\alpha) \tau}{(1+\rho \beta) \rho \alpha L}\right]+\left(1-\delta_{G}\right)\left(x^{*}\right)^{\alpha-1} \frac{1}{\varphi}\left[1-\frac{L}{(1+\rho \beta) \alpha}\right]}{-(1-\alpha)\left(x^{*}\right)^{\alpha-2}(1-\tau)\left[1-\frac{L}{(1+\rho \beta) \alpha}\right]-\tau \alpha\left(x^{*}\right)^{\alpha-1}\left[1-\frac{(1-\varphi)(1-\alpha) \tau}{(1+\rho \beta) \rho \alpha L}\right]}\right] \\
\frac{d g}{d \tau}=\varphi(1-\alpha)\left(x^{*}\right)^{\alpha}\left\{\frac{\alpha \tau}{\left(x^{*}\right)}\left[\frac{\left(x^{*}\right)^{\alpha}\left[1-\frac{(1-\varphi)(1-\alpha) \tau}{(1+\rho \beta) \rho \alpha L}\right]+\left(1-\delta_{G}\right)\left(x^{*}\right)^{\alpha-1} \frac{1}{\varphi}\left[1-\frac{L}{(1+\rho \beta) \alpha}\right]}{-(1-\alpha)\left(x^{*}\right)^{\alpha-2}(1-\tau)\left[1-\frac{L}{(1+\rho \beta) \alpha}\right]-\tau \alpha\left(x^{*}\right)^{\alpha-1}\left[1-\frac{(1-\varphi)(1-\alpha) \tau}{(1+\rho \beta) \rho \alpha L}\right]}\right]+1\right\}
\end{gathered}
$$

Where $\frac{\tau}{x^{*}} \frac{d x^{*}}{d \tau}$ indicates the elasticity of tax for $x^{*}$. It has to be positive to achieve positive growth. The condition of $\frac{d x^{*}}{d \tau}>\mathbf{0}$ is same as (43). $\left[\boldsymbol{\varphi}<\mathbf{1}-\frac{(\mathbf{1}+\boldsymbol{\rho} \boldsymbol{\beta}) \boldsymbol{\alpha} \boldsymbol{\rho} L}{(\mathbf{1}-\boldsymbol{\alpha}) \boldsymbol{\tau}}\right]$ 
On the other hand, in the case of labor income tax, growth from tax will be possible provided some conditions are required. Same as the case of capital income tax there are two effects. First is "A: push-up effect" as same as in the case of capital income tax. Second are two kinds of effect which decrease private capital. They have also two roots. (1) The decrease disposable income with tax. (2) The increase income in $2^{\text {nd }}$ period with public pension. In the case of labor income tax if the effect " $\mathrm{A}$ " exceeds the effect " $\mathrm{B}$ " the growth rate will rise with tax. But it required the strict condition. Details of this are described in the next section.

\section{Proposition 2}

The growth rate will be positive if the elasticity of labor income tax for $x^{*}$ is to be positive. But for that, condition is required.

\section{Numerical Approach}

I calculate condition (43) with numerical approach. According to Cabinet Office (2020) ${ }^{3}$, Mai Chi Dao et.al.(2017) and Maebayashi(2013) three cases are set out as follows.

\begin{tabular}{|c|c|c|c|c|c|c|c|}
\hline & $\alpha$ & $\rho$ & $\beta$ & $\delta_{G}$ & $\mathrm{~T}$ & $L$ & condition \\
\hline Case 1 & 0.4 & .07 & 0.8 & 0.4 & 0.1 & 1 & $\varphi_{1}<-6$ \\
\hline Case 2 & 0.4 & 0.7 & 0.8 & 0.4 & 0.1 & 0.67 & $\varphi_{2}<-7$ \\
\hline Case 3 & 0.05 & 0.7 & 0.8 & 0.4 & 0.1 & 0.67 & $\varphi_{3}<0.99$ \\
\hline
\end{tabular}

Mai Chi Dao et.al.(2017) indicated the ratio of the share of capital and labor was 4:6 in 1970, but it is currently at 6:4. This means that AI and IT related companies currently increases innovations. This will then replace labor, with relatively cheaper capital. Cabinet Office (2020) anticipates that the number of people in Japan will be reduced to two-thirds of the current population by 2070 , and the working force will decrease drastically because of an aging society. Case 1 and Case 2 can't fulfill the condition because the sign is negative. Though Case 3 fulfills requirements $(\varphi \leq 1)$, capital share requires a number less than 0.05. This is not suitable for current economic situation.

\section{Proposition 3}

The economy where government tax labor income will not grow, if government can't spend a lot of public capital investment, and the capital share required is a very low value.

\section{Social Welfare}

\subsection{In the Case of Capital Income Tax}

Social welfare function is as follow where $\theta$ is a social discount rate and the price of $\mathrm{w}$ and $\mathrm{r}$ are constant because it is determined by each market. Where I indicate

$$
U_{t}=\theta^{t} \sum_{t=0}^{\infty}\left(\log c_{t}+\frac{\beta \rho}{\theta} \log d_{t}\right)
$$

3 "Changes in total population and population structure" Cabinet Office(2020)

(https://www8.cao.go.jp/shoushi/shoushika/whitepaper/measures/w-2018/30webhonpen/html/b1_s1-1-1.html)

(accessed on September 1, 2020) 


$$
\begin{gathered}
c_{t}^{*}=\frac{w[1+r(1-\tau)]+r \tau(1-\varphi)}{[1+r(1-\tau)](\rho+1)} \\
d_{t}^{*}=\frac{\rho w[1+r(1-\tau)]+\rho r \tau(1-\varphi)}{\beta(\rho+1)}+\frac{r \tau(1-\varphi)}{\beta}
\end{gathered}
$$

(51) is shown as follows by infinite geometric series sum.

$$
\begin{gathered}
U_{t}=\frac{1}{1-\theta}\left[\log c_{t}^{*}+\frac{\beta \rho}{\theta(1-\theta)} \log d_{t}^{*}\right] \\
U_{t}=\frac{1}{1-\theta} \log \left[\frac{w[1+r(1-\tau)]+r \tau(1-\varphi)}{[1+r(1-\tau)](\rho+1)}\right] \\
+\frac{\beta \rho}{\theta \beta(1-\theta)} \log \left\{\frac{\rho w[1+r(1-\tau)]+\rho r \tau(1-\varphi)}{(\rho+1)}+r \tau(1-\varphi)\right\}
\end{gathered}
$$

The effect for social welfare on capital income tax is given by the next equation: Where I indicate $\tau_{1}$ as capital income tax.

$$
\begin{aligned}
& \frac{d U_{t}}{d \tau_{1}}= \frac{(1-\alpha)\left(x^{*}\right)^{\alpha} G_{0}\left[1+\alpha\left(x^{*}\right)^{\alpha-1}\left(1-\tau_{1}\right)\right]+\alpha\left(x^{*}\right)^{\alpha-1} \tau_{1} L(1-\varphi)}{(1-\theta)(1-\rho) L} \\
& \times\left\{\alpha\left(x^{*}\right)^{\alpha-1}(1-\varphi)-\left[1+\alpha\left(x^{*}\right)^{\alpha-1}\left(1-\tau_{1}\right)\right](1-\alpha)\left(\frac{G_{0}}{L}\right) \alpha\left(x^{*}\right)^{2 \alpha-1}\right] \\
&\left.+\frac{\alpha\left(x^{*}\right)^{2 \alpha-1}(1-\alpha)\left(\frac{G_{0}}{L}\right)\left[1+\alpha(x)^{\alpha-1}\left(1-\tau_{1}\right)\right]+\alpha\left(x^{*}\right)^{\alpha-1} \tau_{1}(1-\varphi)}{\left[1+\alpha\left(x^{*}\right)^{\alpha-1}\left(1-\tau_{1}\right)\right]}\right\}
\end{aligned}
$$

The condition for (56) to be positive is as follows.

$$
\frac{(1-\varphi) L}{\left[1+\alpha\left(x^{*}\right)^{2 \alpha-1}\left(1-\tau_{1}\right)\right](1-\alpha) G_{0}}+\frac{\left[1+\alpha\left(x^{*}\right)^{\alpha-1}\left(1-\tau_{1}\right)\right](1-\alpha)\left(x^{*}\right)^{\alpha} G_{0}+\tau L(1-\varphi)}{\left[1+\alpha\left(x^{*}\right)^{\alpha-1}\left(1-\tau_{1}\right)\right]^{2}(1-\alpha)\left(x^{*}\right)^{\alpha} G_{0}}>1
$$

\subsection{In the Case of Labor Income Tax}

The optimal consumption in each period is as follows.

$$
\begin{gathered}
c_{t}^{*}=\frac{w(1+r)+r(1-\varphi)}{(1+r)(\rho+1)} \\
d_{t}^{*}=\frac{\rho w \tau_{2}(1+r)+\rho r(1-\varphi)}{\beta(\rho+1)}+\frac{w \tau_{2}(1-\varphi)}{\beta}
\end{gathered}
$$

I assign the effect for social welfare of labor income tax, where I indicate $\tau_{2}$ as labor income tax. 


$$
\begin{aligned}
& \frac{d U_{t}}{d \tau_{2}}=\frac{1}{(1-\theta)(\rho+1)}\left[\frac{\left[1+\alpha\left(x^{*}\right)^{\alpha-1}\right](1-\alpha)\left(x^{*}\right)^{\alpha} G_{0}}{(1-\alpha)\left(x^{*}\right)^{\alpha} G_{0} \tau_{2}\left[1+\alpha\left(x^{*}\right)^{\alpha-1}\right]+\alpha\left(x^{*}\right)^{\alpha-1}(1-\varphi) L}\right]+\frac{\rho L}{\theta(1-\theta)(1+\rho)} \times \\
& {\left[\frac{1}{\rho(1-\alpha)\left(x^{*}\right)^{2 \alpha+2} G_{0}(1-\alpha)\left(1+\alpha\left(x^{*}\right)^{\alpha-1}\right)+\alpha\left(x^{*}\right)^{\alpha-1} \rho \tau_{2} L+(1-\alpha)\left(x^{*}\right)^{\alpha} G_{0} \tau_{2}(1-\varphi)(\rho+1)}\right]>0}
\end{aligned}
$$

\section{Proposition 4}

Taxation of labor income makes social welfare increase with no condition, though taxation of capital income needs condition to increase social welfare.

\section{Concluding Remarks}

The intuitive effects for growth are the same in both cases. In the case of capital income tax, if the GDP boost effect with increase of public capital investment is larger than decrease effect in private capital with decline interest rate and increase of pension, then the growth rate is positive. In other words the elasticity of tax for $\mathrm{x}$ will be positive, with no conditions. In the case of labor income tax, if the GDP boost effect is larger than the effect of private capital reduction effect with decline disposable income and increase of pension. The important point of this paper is the condition of the share rate of government which is indicated by public capital investment and public pension. The condition is very severe considering the current economic situation where capital share is large and population declining. However, it may happen that labor income tax is desirable. Taxing labor income is better regarding there is no condition to increase social welfare.

\section{Acknowledgements}

I am grateful to two anonymous referees and Nikki Gibbs, the editor of this journal for their helpful comments and suggestions. I wish to thank Masaya Yasuoka, Tetsugen Haruyama, and seminar participants of the Kobe Macroeconomics Study Group. I acknowledge the financial support from the research expenses of Nippon Bunri University. I am responsible for all remaining errors.

\section{References}

Barro, R. J. (1990). Government spending in a simple model of endogenous growth. Journal of Political Economy, 98, 103-125. https://doi.org/10.1086/261726

Barro, R. J., \& Sala-i-Martin, X. (1992). Public finance in models of economic growth. Review of Economic Studies, 59, 645-661. https://doi.org/10.2307/2297991

Blanchard, O. J. (1985). Debt, deficits, and finite horizons. Journal of Political Economy, 93, 223-247. https://doi.org/10.1086/261297

de la Croix, D., \& Michel, P. (2002). A theory of economic growth. Dynamics and policy in overlapping generations. Cambridge: Cambridge University Press. https://doi.org/10.1017/CBO9780511606434

Diamond. (1965). National Debt in a Neoclassical Growth Model. American Economic Review, 55(5), 1126-1150.

Docquier, F., Paddison, O., \& Pestieau, P. (2007). Optimal accumulation in an endogenous growth setting with human capital. Journal of Economic Theory, 134, 361-378. https://doi.org/10.1016/j.jet.2006.03.008

Futagami, K., Morita, Y., \& Shibata, A. (1993). Dynamic analysis of an endogenous growth model with public capital. The Scandinavian Journal of Economics, 95, 607-625. https://doi.org/10.2307/3440914

Kamiguchi, A., \& Tamai, T. (2019). Public investment, public debt, and population aging under the golden rule of public finance. Journal of Macroeconomics, 60, 110-122. https://doi.org/10.1016/j.jmacro.2019.01.011

Maebayashi, N. (2013). Public capital, public pension, and growth. International Tax and Public Finance, 20, 89-104. https://doi.org/10.1007/s10797-012-9216-1

Mai Chi Dao et.al. (2017). Why Is Labor Receiving a Smaller Share of Global Income? Theory and Empirical Evidence. IMF Working Paper. 
Pecchenino, P., \& Pollard, R. (1997). The effects of annuities, bequests, and aging in an overlapping generations model of endogenous growth. Economic Journal, 107, 26-46. https://doi.org/10.1111/1468-0297.00140

Pecchenino, P., \& Utendorf, K. (1999). Social security, social welfare and the aging population. Journal of Population Economics, 12, 607-623. https://doi.org/10.1007/s001480050116

Romer, P. M. (1986). Increasing Returns and Long Run Growth. Journal of Political Economy, 94, 1002-37. https://doi.org/10.1086/261420

Turnovsky, S. J. (1997). Fiscal policy in a growing economy with public capital. Macroeconomic Dynamics, 1, 615-639. https://doi.org/10.1017/S1365100597004045

Yaari, M. E. (1965). Uncertain lifetime, life insurance, and the theory of the consumer. Review of Economic Studies, 32, 137-150. https://doi.org/10.2307/2296058

Yakita, A. (2001). Uncertain lifetime, fertility and social security. Journal of Population Economics, 14, 635-640. https://doi.org/10.1007/s001480000049

Yakita, A. (2008). Aging and public capital accumulation. International Tax and Public Finance, 15, 582-598. https://doi.org/10.1007/s10797-007-9041-0

\section{Copyrights}

Copyright for this article is retained by the author(s), with first publication rights granted to the journal.

This is an open-access article distributed under the terms and conditions of the Creative Commons Attribution license which permits unrestricted use, distribution, and reproduction in any medium, provided the original work is properly cited. 